\title{
Potential solutions to problems posed by the offspring sex ratios of people with parasitic and viral infections
}

\author{
William H. James
}

The Galton Laboratory, Department of Genetics, Evolution and Environment, University College London, Wolfson House, 4 Stephenson Way, London NW1 2HE, UK

\begin{abstract}
I have hypothesized that mammalian offspring sex ratios (proportions male at birth) are partially controlled by the hormone levels of both parents around the time of conception. Recently data have been published (privately) which impugn suggestions of mine (based on that hypothesis) relating to the offspring sex ratios of people who are carriers of hepatitis B virus; and (publicly) to hormone profiles of women who are infected with the protozoan parasite Toxoplasma gondii. Here these data are reviewed in the light of data on offspring sex ratios of people infected with hepatitis $\mathrm{C}$, and cytomegalovirus and T. gondii; and of mice with T. gondii and the trichostrongyline nematode Heligmosomoides polygyrus. Three proposals are made viz: 1 . Women infected with $T$. gondii may have high oestrogen levels. This would potentially explain reports of their high offspring sex ratios, long gestations and (perhaps) behavioural traits. 2. Some of these infective organisms may 'prefer' a particular endocrine environment in their host (in the sense that it facilitates replication or transmission or both). 3. Some of these organisms apparently cause changes in that endocrine environment as a consequence of their presence. If both the latter two proposals were correct, it could explain recent puzzling data on the offspring sex ratios of hepatitis B carriers. And if this solution turns out to be correct, it would suggest new endocrine means of combating hepatitis B infection.
\end{abstract}

Keywords: cytomegalovirus CMV, Heligmosomoides polygyrus, hepatitis B virus HBV, hepatitis C virus HCV, sex ratio at birth, Toxoplasma gondii

Human beings and other mammalian species are subject to viral and parasitic infections which are associated with changes in the hosts' offspring sex ratios at birth. Such changes have been reported in relation to hepatitis $\mathrm{B}$, hepatitis $\mathrm{C}$, cytomegalovirus and the protozoan parasite Toxoplasma gondii in man; and to T. gondii and the trichostrongyline nematode Heligmosomoides polygyrus in the mouse. The causes of these sex ratio changes are not established. However, the health burdens imposed by some of these agents are heavy, and an understanding of this sex ratio variation may suggest treatments for the various pathologies. So it seemed worth considering these topics in a single context because the data on each may throw light on interpretation of the others. The present note will later focus on new data on offspring sex ratios of hepatitis B carriers, and new data on hormone levels of T. gondii-infected women, so other forms of infection will be considered first.

There is now strong evidence that (at least under some circumstances) mammalian (including human) sex ratios (proportions male) at birth are associated with the hormone levels of both parents around the time of conception (James 1996, 2004, 2008a, b). Ex hypothesi, high levels of testosterone ( $\mathrm{T}$ ) (in either parent) or oestrogen (E) (in mothers) around the time of conception are associated with the subsequent births of sons, and low levels with daughters. Offspring sex ratios of hosts infected with each of the above agents will now be considered in the light of that hypothesis.

\section{Mice infected with Heligmosomoides polygyrus}

Ehman and Scott (2002) found that litters sired by male mice parasitized by this nematode had significantly low offspring sex ratios. Parasitic infection of male mammals (including mice) generally lowers their T levels (Hilgarth and Wingfield 1997, Barnard et al. 1998). In conformity with my hypothesis, it seems reasonable to ascribe the low offspring sex ratio to the low T concentrations. Thus these data not only support my hypothesis: they also support one of the proposals offered in the Abstract above - viz that the infective agent alters the host's hormone concentrations.

\section{Cytomegalovirus (CMV)}

Women who are seropositive for cytomegalovirus (CMV) reportedly produce a significant excess of daughters (Piazze et al. 1999, Shields et al. 2002). Oestrogen has a generally suppressive effect on CMV replication (Speir et al. 2000). So oestrogen levels may be assumed 
to be low in CMV-seropositive women: hence ex hypothesi, their low offspring sex ratio. I know no evidence on whether the virus, once present, alters oestrogen levels in women, nor on whether offspring sex ratio alters with duration of infection.

\section{Hepatitis C virus (HCV)}

I know only one published set of data on the sexes of offspring born to women infected with hepatitis C. The European Paediatric Hepatitis C Virus Network (2005) reported 802 boys and 668 girls born to infected women. This sex ratio (proportion male) of 0.546 yields a chisquared value of 6.2 , with $1 \mathrm{df}, \mathrm{p}<0.02$, tested against an expected contemporary European live birth sex ratio of 0.513 (Parazzini et al. 1998). The difference between these two sex ratios (0.033) is small but typical of much established human sex ratio variation. The evidence is weak, but one might speculate that this unusual offspring sex ratio has an endocrine basis (as would be suggested by my hypothesis). Analogously, Blumberg (2006) noted sex differences in morbidity and mortality from hepatitis $\mathrm{B}$ which he suggested might have endocrine bases. Other evidence is that hepatitis C (like hepatitis B) is a powerful risk factor for hepatocellular cancer (HCC) (Kumada et al. 2009). Moreover, men who are destined to develop HCC have significantly higher T levels than controls (Yuan et al. 1995, Yu et al. 2001). So it is suggested here that (at least at the time infection is initiated) HCV, like $\mathrm{HBV}$, is associated with high $\mathrm{T}$ levels.

\section{Human and murine infection with Toxoplasma gondii}

This parasite is common in human beings, between $20 \%$ and $60 \%$ of the populations of most developed countries being infected (Flegr et al. 2005a). Kaňková et al. (2007a) reported that (as contrasted with uninfected controls), infected women are more likely to produce sons $(\mathrm{p}=0.001$ ), and that the offspring sex ratio (proportion male) increases with the concentration of anti-Toxoplas$m a$ antibodies in $T$. gondii-positive mothers $(p=0.001)$. This group of workers also reported similar findings on experimentally infected female mice (Kaňková et al. 2007b). Most importantly (and hitherto unexplained) they also found a high murine offspring sex ratio in early phases of the infection and a low offspring sex ratio in later phases of the infection.

Until recently, it had been generally supposed that the testosterone (T) levels of infected people are high. The grounds for this supposition are now summarised.

1. Flegr et al. (2005a) reported that infected men and women (as contrasted with uninfected controls) have lower values of Manning's $R$ (where $R=2 \mathrm{D} / 4 \mathrm{D}$ ) where $2 \mathrm{D}$ is the length of the 2 nd digit, and $4 \mathrm{D}$ the length of the 4th digit. Manning had reported that low values of $R$ are associated with high circulating T values (Manning et al. 1998, Manning 2002). [In parenthesis, it may be remarked that Manning's finding is consistent with my hypothesis in that he reported that men's $R$ values correlate significantly and negatively with their offspring sex ratios (Manning et al. 2002)].

2. Hodková et al. (2007) reported a higher perceived dominance rating in infected men, and interpreted this as evidence that they had higher T levels.

3. Flegr et al. (2005a) also reported that $R$ correlated negatively with anti-Toxoplasma antibodies in $T$. gondiifree subjects. Moreover these authors found that infected men were significantly taller than uninfected controls. So they concluded that their 'results suggest that some of the observed differences between infected and non-infected subjects may have existed before infection and could be caused by the lower natural resistance to $T$. gondii infection in subjects with high prenatal testosterone (T) levels'. So, in accordance with my hypothesis, I suggested that the high offspring sex ratio of infected women may be due to their (supposedly) high T levels (James 2008b). However that suggestion has been impugned as will now be described.

Recent research suggests that hormone characteristics may differ as between infected men and women. Flegr et al. (2008b) reported that $T$. gondii-infected men have higher $\mathrm{T}$ levels than uninfected controls; and that T. gondii-infected women have significantly lower $\mathrm{T}$ levels than uninfected controls. These authors speculated that these endocrine differences might explain the established differences in reported behaviour between infected men and women (e.g. Lindová et al. 2006). This explanation will later be examined and supplemented.

What causes these behavioural differences between infected men and women? Here I shall focus on the reported hormonal antecedents and consequences of $T$. gondii infection in people and rodents. In particular I shall examine the possibility that infected female mammals have high oestrogen levels.

There is good evidence that (in rodents at least) oestrogen (as well as testosterone) has a role in $T$. gondii infection. For instance, Kittas and Henry (1980) reported greater resistance to T. gondii infection in gonadectomised mice (of both sexes) than in control mice. These workers also reported that infected mice treated with hexoestrol suffered overwhelming toxoplasmosis with increased mortality. Moreover, Pung and Luster (1986) confirmed that pharmacological levels of oestrogen lower resistance to such infection in mice. So one may speculate that, at the time of infection, infected mice have higher levels of oestrogen than uninfected controls on the average. However, once infected, females develop ovarian dysfunction (Stahl et al. 1995a) and uterine atrophy which is reversed by the administration of oestradiol (Stahl et al. 1995b). So I suggest that if the date of infection is taken as time origin, oestrogen concentrations in infected female mice decrease across time from above average to below average 
(as contrasted with uninfected controls). If this were so, it would explain (on the basis of my hypothesis) the finding of a high offspring sex ratio in infected mice in the early phase of infection, and a low offspring sex ratio in the later phases (Kaňková et al. 2007b). This constitutes indirect evidence that infected female mice show evidence for two of the proposals in the Abstract viz that $T$. gondii 'prefers' hosts to have high E levels, and that $T$. gondii lowers these E levels.

The question arises whether it is reasonable to conjecture, on the basis of their reported behaviour, that (at the time of infection by $T$. gondii), women (as is suggested above in respect of infected female mice) may also have high oestrogen levels. For, if my hypothesis were accepted, that would also potentially explain the high offspring sex ratio of infected women reported by Kaňková et al. (2007a).

There is good evidence that prenatal (Reinisch 1977) and postnatal oestrogen levels affect women's personalities and behaviour (Linzmayer et al. 2001, Westberg et al. 2003); and that oestrogen acts as a neurotransmitter or neuroprotector (Cyr et al. 2000). Also relevant is the direct evidence from psychometric testing when women's oestrogen levels are manipulated upwards (in hormone replacement therapy) or downwards (in combating breast cancer). The consensus from these studies is that low levels of oestrogen are associated with the pre-menstrual syndrome (Arpels 1996); depression (Swaab et al. 2005); verbal and working memory deficit (Shilling et al. 2003, Grigorova et al. 2006); and lower cognitive ability (Palmer et al. 2008). The consensus is also that high levels of oestrogen reverse these effects. Moreover it seems likely that oestrogen has structural effects on the brain (Ghidoni et al. 2006). So what light is thrown on their endocrinology by the reported behavioural features of women infected with $T$. gondii? I confine the discussion here to replicated results reviewed by Flegr (2007) on work mainly carried out by his team at Charles University during the previous 15 years. This author noted that consistent and significant differences were found between $T$. gondii-infected and uninfected subjects in 9 of 11 studies, and that these differences were not the same for men and women. In brief, these differences were as follows. Infected men showed lower superego strength (were more likely to disregard rules) and were more expedient, suspicious and jealous than uninfected controls. In contrast, infected women had higher superego strength, and were more warm-hearted, affectionate, outgoing and conscientious than comparable controls. I agree with these workers that the established higher testosterone in infected men might well explain the psychometric findings relating to infected and uninfected men (Ellis 1986). However, I doubt whether the psychological differences reported between infected and uninfected women may be explained by the reported lower $\mathrm{T}$ levels in infected women (Flegr et al. 2008a). Instead I wish to propose that the psychological differences between infected and uninfected women are at least partially explained by higher levels of oestrogen in infected women. That would not only explain the high reported offspring sex ratio of infected women (Kaňková et al. 2007a); it also seems a potential explanation of (some of) the behaviour of infected women summarised above. (The reported psychological effects of high levels of oestrogen seem comparable to at least some of that behaviour.) Lastly it seems compatible with the reportedly long durations of gestation of infected women (Flegr et al. 2005b, Kaňková and Flegr 2007). I know no evidence for the suggestion of Flegr (2007) that long pregnancies are associated with high maternal $\mathrm{T}$ levels, whereas $\mathrm{Ni}$ et al. (2002) suggested that high maternal levels of $E$ tend to be associated with term and post-term pregnancies.

I hope this conjecture will prompt those with the available resources to test the notion that infected women have high oestrogen levels. Such a phenomenon may exist if high E levels were to facilitate transmission or replication, women with higher E levels being more vulnerable to infection. Such vulnerability could be simply physiological or it could also be behaviourally mediated, women with high $\mathrm{E}$ engaging in more risky behaviour (Zuckerman 1994) and so more liable to come into contact with the organism.

\section{Hepatitis B virus (HBV)}

When an individual is infected with hepatitis $B$ virus (HBV), one of two sequences of events may occur viz

1. The surface antigen HBsAg disappears from the blood and the antibody (anti-HBs) appears. It protects against further infection, and those carrying it are called 'immune'. OR

2. Little or no anti-HBs is detected, and HBsAg persists in the blood for a long time. Those to whom this happens are called 'carriers'.

Until recently it would have been reasonable to suppose that

1. Hepatitis B carriers (of both sexes) produce statistically significant excesses of sons and

2. Immune people have an excess of daughters (e.g. Blumberg 1979).

These conclusions are based on the results of extensive work by Blumberg and colleagues in a variety of locations (Greece, Philippines, Papua New Guinea, France and Greenland). This work was summarised by Chahnazarian et al. (1988) and Chen et al. (Chen G., Oster E., Yu X., Lin W. 2008: Hepatitis B and sex ratios at birth: revisiting the relationship. Preliminary and incomplete unpublished working paper.) and confirmed by Camargo et al. (2002) who reported a very high offspring sex ratio in rural Brazilian community in which the prevalence of serum positive reactions against hepatitis B was $74 \%$ 
amongst adult males. Moreover it has been reported that there is a statistically significant excess of brothers among the sibs of carriers (Mazzur and Watson 1974, Cazal et al. 1976). Lastly, the conclusion was indirectly strengthened by work of Oster (2005) on sex ratios following vaccination against hepatitis B in Alaska.

However, two unpublished working papers (Chen et al. 2008 unpublished - see above; Oster E., Chen G., Yu X., Lin W. 2008: Hepatitis B does not explain malebiased sex ratios in China. Unpublished working paper.) make it clear that the above conclusions on sex ratios do not apply universally. Two examples will be given.

First, Lin and Luoh (2008) used data from a cohort of 3 million births in Taiwan and found only a very small effect of maternal hepatitis carrier status on offspring sex ratio. Their analysis left open the possibility that paternal carrier status may have some such effect in their sample. Second, Oster et al. (2008 unpublished - see above) did not find evidence for paternal or maternal hepatitis B carrier status on offspring sex ratio in a sample of 67,000 people in a prospective study of liver cancer in China. How may these new data be explained?

There have been two large prospective cohort studies on the relationship between men's testosterone levels and hepatocellular cancer. In them, serum samples were initially taken from respectively 9,691 men in Taiwan (Yu and Chen 1993), and 18,244 men in Shanghai (Yuan et al. 1995). Incidental findings in both these studies were that, at the time of recruitment, healthy volunteer HBV carriers had significantly higher mean $\mathrm{T}$ levels than healthy volunteer uninfected controls $(\mathrm{p}=0.045$, two-way; and $\mathrm{p}=0.0006$, two-way respectively). Thus there can be little doubt that under some circumstances, healthy male HBV carriers have higher T levels than healthy, uninfected controls. So, bearing in mind the substantial evidence for the hypothesis that high parental $\mathrm{T}$ levels around the time of conception predispose parents to produce sons (James 1996, 2004, 2008a, b), it seems reasonable to propose that

A. The high offspring sex ratios of HBV carriers (repeatedly reported by Blumberg and his colleagues) were caused by the carriers' high T levels, and

B. The low reported offspring sex ratio of immune people is due to their low $\mathrm{T}$ levels. The $\mathrm{T}$ level of immune men reported by Yuan et al. (1995) was significantly lower than that of male carriers. (Possibly their low $\mathrm{T}$ is responsible for their transition to immunity.)

The first of these proposals above, (A), is supported by the lower fertility of carrier women and the higher fertility of carrier men reported by Chen et al. (2008 unpublished - see above), as will now be explained. The low reported fertility of carrier women may plausibly be attributed to high testosterone levels because it is well established that there is substantial variation of androgen levels across women, and that impaired fertility is a consequence of even moderately raised levels (Azziz et al. 2006). More- over the higher reported fertility of HBV carrier men may plausibly be attributed to high testosterone levels because testosterone in men is positively associated with a number of components of fecundability (the probability of conception in a month at risk) e.g. coital rate (Potter and Millman 1986, Mantzoras et al. 1995) and sperm quality (Zalata et al. 1995).

The question remains: why did the two more recent studies in Taiwan and China fail to replicate the raised sex ratios of hepatitis B carriers? I hope the forgoing considerations may be thought to justify examining the following suggestions.

1. As noted above, there is good evidence that (at the time of infection) hepatitis B carriers have high testosterone levels. The reason for this is not known, but it seems more likely that the virus (rather than somehow being responsible for the additional $\mathrm{T}$ ) is 'choosy' in the sense that either it replicates faster in, and/or it is transmitted more readily to, such an environment. Moreover people with high T, because of their increased levels of sensationseeking (Zuckerman 1994), would be expected to behave in a manner such as to increase their chances of acquiring infection.

2. The reaction of men to many forms of adverse exposure is a diminution of excretion of testicular T (Semple 1986). So I suggest that, if the date of infection is taken as time origin, T levels of (male) HBV carriers decrease from above average to below average as contrasted with uninfected controls. Ex hypothesi, this would explain the finding of Chahnazarian (1986) (as reported by Klasen 2009) that there is an interaction between offspring sex ratio with parity: such that the raised offspring sex ratio of HBV carriers applies only to early-born offspring.

3. If this line of argument were correct, then the current $\mathrm{T}$ levels of (male) carriers would depend on the duration of infection, and that, in turn, would depend on their age at infection.

4. So if age at infection varied from one location to another, one would expect the $\mathrm{T}$ levels of current carriers to vary accordingly. In particular, men of a given age who were infected as neonates might be expected to have lower $\mathrm{T}$ levels than those who had acquired the virus later in life. Lastly it is clear that age at infection is earlier in the Asia-Pacific region where, according to Leung (2009) 'half of the chronic hepatitis $\mathrm{B}$ infection burden results from vertical, or mother-to-child transmission, with early child horizontal transmission accounting for the remaining half'. In contrast, Stefos et al. (2009) estimated in regard to a sample of Greek carriers that vertical transmission accounted for only $34 \%$, and later transmission for the remainder. In other words, one would estimate that mean age at infection is lower in the Asia-Pacific region than in Greece. I suggest that this may account for the recent failures to replicate the sex ratio phenomenon in China and Taiwan. 


\section{Further research}

Research suggestions made above are now summarised. Three types of infection are considered: 1. Toxoplasma gondii, 2. Hepatitis C, and 3. Hepatitis B.

\section{Toxoplasma gondii}

A. It would be useful if further research were directed at assessing the T levels of women infected with $T$. gondii. It would also be useful to assess whether the oestrogen (E) levels of infected women are high, and especially whether the concentrations of anti-Toxoplasma antibodies in T. gondii-positive women correlate with their E levels.

B. It would be useful if the offspring sex ratios of infected men were assessed. On the bases of my hypothesis and of their high T levels, I predict that infected men would sire a high proportion of sons - at least early in infection.

C. It would be useful to know whether direct data support the suggestion above that the oestrogen levels of mice infected with $T$. gondii are initially high, and decline during the course of infection.

\section{Hepatitis C}

As suggested above, the testosterone concentrations of men and women infected with this virus should be assayed. I would predict them to be high as contrasted with uninfected controls. Longitudinal studies should contrast the secular progress of testosterone concentrations in healthy infected subjects with those in healthy uninfected controls because it is important to know whether the $\mathrm{T}$ levels of infected subjects decline appreciably with duration of infection.

\section{Hepatitis B}

The temporal changes of T levels in carriers should also be studied. This should be done in both men and women. If they decline more rapidly than those of healthy controls (from above average at infection to below average), they might explain the perplexing data reported in Professor Oster's two recent unpublished papers.

Acknowledgments. I am grateful to Professor B.S. Blumberg (Fox Chase Cancer Center) and Professor J. Flegr (Charles University, Prague) for helpful correspondence and sending me copies of their papers. I am indebted to Professor M.-L. Newell (Institute of Child Health, London) for drawing my attention to the high offspring sex ratio of women infected with hepatitis C. I am grateful to Professor Emily Oster (Chicago University) for sending me copies of her two working papers cited in the text above, and for helpful correspondence and encouragement. I am grateful to Dr. S. Seth (National Institute of Technology, India) for drawing my attention to Professor Oster's recent work, and for sending me a copy of the essay of Klasen (2009). Lastly I am indebted to two reviewers for their encouraging and helpful comments.

\section{REFERENCES}

Arpels J.C. 1996: The female brain hypoestrogenic continuum from the premenstrual syndrome to menopause. J. Reprod. Med. 41: 633-639.

Azziz R., Nestler J.E., Dewailly D. (Eds.) 2006: Androgen Excess Disorders in Women: Polycystic Ovary Syndrome and Other Disorders. Second Edition. Humana Press, Totowa, New Jersey, $466 \mathrm{pp}$.

Barnard C.J., Behnke J.M., Gage A.R., Brown H., Smithurst P.R. 1998: The role of parasite-induced immunodepression, rank and social environment in the modulation of behaviour and hormone concentrations in male laboratory mice (Mus musculus). Proc. R. Soc. Lond., Ser. B, 265: 693-701.

Blumberg B.S. 1979: Sex differences in response to hepatitis B virus. 1. History. Arth. Rheum. 22: 1261-1266.

Blumberg B.S. 2006: The curiosities of hepatitis B virus: prevention, sex ratio and demography. Proc. Am. Thoracic Soc. 3: $14-20$.

Camargo L.M.A., Moura M.M., Engracia V., Pagotto R.C., Basano S.A., Da Silva L.H.P., Camargo E.P., Beiguelman B., Krieger H. 2002: A rural community in a Brazilian Western Amazonian region: some demographic and epidemiological patterns. Mem. Inst. Oswaldo Cruz 97: 193-195.

Cazal P., Lemaire J.M., Robinet-Levy M. 1976: Hepatitis B et rapport du masculinite. Rev. Fr. Transfus. Immunohematol. 19: 577-581.

Chahnazarian A. 1986: Determinants of the sex ratio at birth. Unpublished $\mathrm{PhD}$ dissertation, Princeton University, Princeton, N.J.
Chahnazarian A., Blumberg B.S., London W.T. 1988: Hepatitis B and the sex ratio at birth: a comparative analysis of four populations. J. Biosoc. Sci. 20: 357-370.

Cyr M., Calon F., Morisette M., Di Paolo T., Callier S. 2000: Drugs with estrogen-like potency and brain activity: potential therapeutic applications for the CNS. Curr. Pharm. Des. 6: $1287-1312$.

Eнman K.D., Sсотт M.E. 2002: Female mice mate preferentially with non-parasitized males. Parasitology 125: 461-466.

ELLIS L. 1986: Evidence of neuroandrogenic etiology of sex roles from a combined analysis of human, nonhuman primate and nonprimate mammalian studies. Pers. Indiv. Differ. 7: 519-552.

European Paediatric Hepatitis C Virus Network. 2005: A significant sex - but not elective Cesarean section - effect on mother-to-child transmission of hepatitis $\mathrm{C}$ virus infection. J. Infect. Dis. 192: 1872-1879.

FLEGR J. 2007: Effects of Toxoplasma on human behaviour. Schiz. Bull. 33: 757-760.

Flegr J., Hrdá Š., Kodym P. 2005b: Influence of latent 'asymptomatic' toxoplasmosis on body weight of pregnant women. Folia Parasitol. 52: 199-204.

Flegr J., Hrušková M., Hodný Z., Novotná M., Hanušová J. 2005a: Body height, body mass index, waist-hip ratio, fluctuating asymmetry and second to fourth digit ratio in subjects with latent toxoplasmosis. Parasitology 130: 621-628.

Flegr J., Lindová J., Kodym P. 2008a: Sex dependent toxoplasmosis-associated differences in testosterone concentrations in humans. Parasitology 135: 427-431. 
Flegr J., Lindová J., PivoñKová V., Havlíček J. 2008b: Latent toxoplasmosis and salivary testosterone concentrations: important confounding factors in second to fourth digit ratios. Am. J. Phys. Anthropol. 137: 479-489.

Ghidoni R., Boccardi M., Benussi L., Testa C., Villa A., Pievani M., Gigola L., Sabattoli F., Barbiero L., Frisoni G.B., Binetti G. 2006: Effects of estrogens on cognition and brain morphology: involvement of the cerebellum. Maturitas 54: 222-228.

Grigorova M., Sherwin B.B., Tulandi T. 2006: Effects of treatment with leuprolide acetate depot on working memory and executive functions in young premenopausal women. Psychoneuroendocrinology 31: 935-947.

Hillgarth N., Wingfield J.C. 1997: Parasite-mediated sexual selection: endocrine aspects. In: D.H. Clayton and J. Moore (Eds.), Host-Parasite Evolution: General Principles and Avian Models. Oxford University Press, New York, pp. 78-104.

Hodková H., Kolbeková P., Skallová A., Lindová J., Flegr J. 2007: Higher perceived dominance in Toxoplasma-infected men: new evidence for role of increased testosterone in toxoplasmosis-associated changes in human behavior. Neuroendocrinol. Lett. 28: 110-114.

JAMES W.H. 1996: Evidence that mammalian sex ratios at birth are partially controlled by parental hormone levels at the time of conception. J. Theor. Biol. 180: 271-286.

JAMES W.H. 2004: Further evidence that mammalian sex ratios at birth are partially controlled by parental hormone levels around the time of conception. Hum. Reprod. 19: 1250-1256.

JAmES W.H. 2008a: Evidence that mammalian sex ratios at birth are partially controlled by parental hormone levels around the time of conception. J. Endocrinol. 198: 3-15.

JAMES W.H. 2008b: Further evidence for the hypothesis that parental hormone levels around the time of conception are associated with human sex ratios at birth. J. Biosoc. Sci. 40: 855-861.

KaŇKOVÁ Š., FLEGR J. 2007: Longer pregnancy and slower fetal development in women with latent "asymptomatic" toxoplasmosis. BMC Infect. Dis. 7, 114.

Kaňková Š., Šulc J., Nouzová K., Fajfrlík K., Frynta D., FleGR J. 2007a: Women infected with parasite Toxoplasma have more sons. Naturwissenschaften 94: 122-127.

Kaňková Š., Kodym P., Frynta D., VavŘinová R., Kuběna A., FLEGR J. 2007b: Influence of latent toxoplasmosis on the secondary sex ratio in mice. Parasitology 134: 1709-1717.

Kittas C., Henry L. 1980: Effect of sex hormones on the response of mice to infection with Toxoplasma gondii. Br. J. Exp. Pathol. 61: 590-600.

Klasen S. 2009: Missing women: some recent controversies on levels and trends in gender bias in mortality. In: K. Basu and R. Kanbur (Eds.), Arguments for a Better World. Essays in Honor of Amartya Sen. Vol. 2. Oxford University Press, New York, pp. $280-302$.

Kumada T., Toyoda H., Kiriyama S., Sone Y., Tanikawa M., Hisanaga Y., Kanamori A., Atsumi H., Takagi M., Nakano S., Arakawa T., Fujimori M. 2009: Incidence of hepatocellular carcinoma in hepatitis $\mathrm{C}$ carriers with normal alanine aminotransferase levels. J. Hepatol. 50: 729-735.

Leung N. 2009: Chronic hepatitis B in Asian women of childbearing age. Hepatol. Int. 3: S24-S31.

Lin M.-J., LuoH M.-C. 2008: Can hepatitis B mothers account for the number of missing women? Evidence from three million newborns in Taiwan. Am. Econ. Rev. 98: 2259-2273.

Lindová J., Novotná M., Havlíček J., Jozífková E., Skallová A., Kolbeková P., Hodný Z., Kodym P., Flegr J. 2006: Gen- der differences in behavioural changes induced by latent toxoplasmosis. Int. J. Parasitol. 36: 1485-1492.

Linzmayer L., Semlitsch H.V., Saletu B., Bock G., SaletuZyhlarz G., Zoghlami A., Gruber D., Metka M., Huber J., Oettel M., Graser T., Grunberger J. 2001: Double blind, placebo-controlled psychometric studies on the effects of a combined estrogen-progestin regimen versus estrogen alone on performance, mood and personality of menopausal syndrome patients. Arzneim.-Forsch. - Drug Res. 51: 238-245.

Manning J.T. 2002: Digit Ratio: a Pointer to Fertility, Behavior and Health. Rutgers University Press, London, 208 pp.

Manning J.T., Martin S., Trivers R.L., Soler M. 2002: 2nd to 4th digit ratio and offspring sex ratio. J. Theor. Biol. 217: 93-96.

Manning J.T., Scutt D., Wilson J., Lewis-Jones D.I. 1998: The ratio of 2 nd to 4 th digit length: a predictor of sperm numbers and concentrations of luteinizing hormone and oestrogen. Hum. Reprod. 13: 3000-3004.

Mantzoras C.S., Georgiadis E.I., Trichopoulos D. 1995: Contribution of dihydrotestosterone to male sexual behaviour. Br. Med. J. 310: 1289-1291.

MazzUR S., Watson T.M. 1974: Excess males among sibs of Australia antigen carriers. Nature 250: 60-61.

Ni X., Nicholson R.C., King B.R., Chan E.C., Read M.A., Sмiтн R. 2002: Estrogen represses whereas the estrogen-antagonist ICI 182780 stimulates CRH gene expression. J. Clin. Endocr. Metab. 87: 3774-3778.

Oster E. 2005: Hepatitis B and the case of the missing women. J. Polit. Econ. 113: 1163-1216.

Palmer J.L., Trotter T., Joy A.A., Carlsen L.E. 2008: Cognitive effects of Tamoxifen in pre-menopausal women with breast cancer compared to healthy controls. J. Cancer Surviv. 2: $275-282$.

Parazzini F., La Vecchia C., Levi F., Franceschi S. 1998: Trends in male:female ratio among newborn infants in 29 countries from five continents. Hum. Reprod. 13: 1394-1396.

Piazze J., Nigro G., Mazzocco M., Marchiani E., Brancato V., Anceschi M.M., Cosmi E.V. 1999: The effect of primary cytomegalovirus infection on fetal lung maturity indices. Early Hum. Dev. 54: 137-144.

Potter R.G., Millman S.R. 1986: Fecundability and the frequency of marital intercourse: new models incorporating the aging of gametes. Popul. Stud. 40: 159-170.

Pung O.J., Luster M.T. 1986: Toxoplasma gondii: decreased resistance to infection in mice due to estrogen. Exp. Parasitol. 61: 48-56.

ReinisCh J.M. 1977: Prenatal exposure of human foetuses to synthetic progestin and oestrogen affects personality. Nature 266: $561-562$.

Semple C.G. 1986: Hormonal changes in non-endocrine disease. Br. Med. J. 293: 1049-1052.

Shields M.D., O’Hare B., Nelson J., Stewart M.C., Coyle P. 2002: Maternal cytomegalovirus seropositivity. Br. Med. J. 325: 335 .

Shilling V., Jenkins V., Fallowfield L., Howell T. 2003: The effects of hormone therapy on cognition in breast cancer. J. Steroid. Biochem. Mol. Biol. 86: 405-412.

Speir E., Yu Z.X., Takeda K., Ferrans V.J., Cannon R.O. 2000: Antioxidant effect of estrogen on cytomegalovirus-induced gene expression in coronary artery smooth cells. Circulation 102: 2990-2996.

Stahl W., Dias J.A., Turek G., Kaneda Y. 1995a: Etiology of ovarian dysfunction in chronic murine toxoplasmosis. Parasitol. Res. 81: 114-120. 
Stahl W., Kaneda Y., Tanabe M., Kumar S.A. 1995b: Uterine atrophy in chronic murine toxoplasmosis due to ovarian dysfunction. Parasitol. Res. 81: 109-113.

Stefos A. 2009: Descriptive epidemiology of chronic hepatitis B by using data from a hepatitis registry in Central Greece. Eur. J. Intern. Med. 20: 35-43.

SwaAb D.F., Bao A.M., Lucassen P.J. 2005: The stress system in the human brain in depression and neurodegeneration. Ageing Res. Rev. 4: 141-194.

Westberg L., Melke J., Landen M., Nilsson S., Baghaei F., Rosmond R., Jansson M., Holm G., Bjorntorp P., Eriksson E. 2003: Association between a dinucleotide repeat polymorphism of the estrogen receptor alpha gene and personality traits in women. Mol. Psychiat. 8: 118-122.

Yu M.W., Chen C.-J. 1993: Elevated serum testosterone levels and risk of hepatocellular cancer. Cancer Res. 53: 790-794.

Received 1 November 2009
Yu M.W., Yang Y.C., Yang S.Y., Cheng S.W., Liaw Y.F., Lin S.M., Chen C.J. 2001: Hormone markers and hepatitis B virus-related hepatocellular carcinoma risk: a nested case-control study among men. J. Natl. Cancer Inst. 93: 1644-1651.

Yuan J.M., Ross R.K., Stanczyk F.Z., Govindarajan S., Gao Y.T., Henderson B.E., Yu M.C. 1995: A cohort study of serum testosterone and hepatocellular carcinoma in Shanghai, China. Int. J. Cancer 63: 491-493.

Zalata A., Hafez T., Verdonck L., Vermeulen L., Comhaire F. 1995: Androgens in seminal plasma: markers of the surface epithelium of the male reproductive tract. Int. J. Androl. 18: 271-277.

Zuckerman M. 1994: Behavioral Expression and Biosocial Bases of Sensation Seeking. Cambridge University Press, New York, $463 \mathrm{pp}$.

Accepted 8 April 2010 